\title{
ENTRE A FENOMENOLOGIA E A HERMENÊUTICA: UMA PERSPECTIVA EM PSICOTERAPIA
}

\author{
Between Phenomenology and Hermeneutics: A Perspective in Psychotherapy \\ Entre la Fenomenología y la Hermenéutica: Una Perspectiva en Psicoterapía
}

Luciana da Silva Mendes Ferreira

\begin{abstract}
Resumo: A discussão sobre a relação da fenomenologia e da hermenêutica com a prática clínica tem sido freqüente entre pesquisadores da psicologia. Tal discussão anuncia a preocupação com métodos mais adequados à aproximação de fenômenos que não são plenamente objetiváveis no sentido naturalista. Entre essas possibilidades, encontra-se a proposta, de inspiração heideggeriana, de conciliação das duas alternativas - a fenomenologia e a hermenêutica - em um único caminho. Porém, essa tentativa de conciliação não se faz sem transformações profundas no que diz respeito à própria fenomenologia de Husserl. Uma vez que o indivíduo é esclarecido como ser-no-mundo, tanto a idéia de uma subjetividade que se relaciona com uma dimensão externa, quando a concepção de interioridade, psique ou mesmo de consciência e intencionalidade, caem por terra. É nesse contexto que a fenomenologia torna-se hermenêutica e seu método passa a apoiar-se no "círculo da compreensão" que pressupõe o fato de já estarmos desde sempre em uma compreensão prévia daquilo que desejamos compreender.

Palavras-chave: Fenomenologia; Hermenêutica; Círculo da Compreensão; Psicoterapia.
\end{abstract}

Abstract: There have been frequent discussions among Psychology researchers on how Phenomenology and Hermeneutics relate with their clinical practice. Such discussion heralds a concern with establishing more adequate methods for the approximation of phenomena that are not fully objectifiable in a naturalistic sense. Among the possibilities for such methods is a proposal, of Heideggerian inspiration, for conciliating both approaches - Phenomenology and Hermeneutics - into a single pathway. However, this attempt at conciliation is not feasible without profound transformations as to what concerns Husserl's Phenomenology itself. Once the individual's existence is clarified as a Being-in-the-World, the idea of a subjectivity that relates to an external dimension, as well as the concepts of interiority, psyche or even conscience or intentionality fall into pieces. It is in this context that Phenomenology becomes Hermeneutics and its method then becomes grounded on the "hermeneutic circle" which states that we always possess some form of previous understanding of that which we wish to comprehend.

Keywords: Phenomenology; Hermeneutics; Hermeneutic Circle; Psychotherapy.

Resumen: La discusión sobre la relación de la fenomenología y de la hermenéutica con la práctica clínica tiene sido frecuente entre pesquisidores de la psicología. Tal discusión anuncia la preocupación con métodos más adecuados a la aproximación de fenómenos que no son plenamente objetivables en el sentido naturalista. Entre esas posibilidades se encuentra la propuesta de inspiración heideggeriana que intenta conciliar las dos alternativas - la fenomenología y la hermenéutica - en un solo camino. Sin embargo esa tentativa de conciliación no sucede sin transformaciones profundas en lo que dice respecto a la propia fenomenología de Husserl. Una vez que se comprende el individuo como ser-en-el-mundo, tanto la idea de una subjetividad que se relaciona con una dimensión externa como la concepción de interioridad, psique o mismo de conciencia y intencionalidad, son echados por tierra. Es en ese contexto que la fenomenología se torna hermenéutica y su método pasa a apoyarse en el "círculo de la comprensión" que presupone el facto de que ya estamos desde siempre en una comprensión previa de lo que nosotros deseamos comprender.

Palabras-clave: Fenomenología; Hermenéutica; Círculo de la Comprensión; Psicoterapia.

Frequentemente, tem-se apresentado a fenomenologia como método psicoterápico alternativo àqueles derivados do positivismo científico, acreditando-se que o método fenomenológico, de inspiração husserliana, possa favorecer uma aproximação mais adequada aos fenômenos psíquicos e às situações existenciais.

Essa crença se funda na própria crítica de Husserl às ciências positivistas. Em A crise das ciências européias e a fenomenologia transcendental (Husserl, 1997), o filósofo mostra que desde Galileu fez-se um recorte físico-matemático do mundo da vida, recorte que foi tomado como a realidade concreta. O problema é que o naturalismo e o objetivismo dessa atitude não alcançam a riqueza que diz respeito a nossa experiência no e do mundo. Como diz Husserl (1997),

Essa ciência não tem nada a nos dizer. Em princípio, ela exclui aqueles problemas que são os mais candentes para o homem, o qual, em nossos tempos atormentados, sente-se à mercê do destino: os problemas do sentido e do não-sentido da existência humana em seu conjunto (p. 187). 
A psicologia, tendo nascido em diálogo com as ciências positivistas herda os mesmos problemas. "As meras ciências de fatos criam meros homens de fato", diz Husserl (1997). Para ele, o papel da filosofia é o de libertar a nossa experiência com o mundo da vida da fetichização da ciência. Caberia à fenomenologia essa tarefa, que se daria por meio do resgate da subjetividade como parte fundamental da nossa compreensão do mundo da vida.

A fenomenologia é, portanto, a filosofia primeira que fundaria todo o nosso conhecimento do mundo da vida e, assim, fundaria também todas as demais ciências. Isso porque o mundo de vida é o último elemento, aquilo que podemos encontrar por trás da reificação objetiva. Como defende o filósofo, "não importa garantir as noções objetivas, aquilo que importa é compreendê-las" (Husserl, 1997, p. 215).

E qual é então o caminho proposto pela fenomenologia husserliana? A "redução fenomenológica" que nos conduz ao conhecimento das essências eidéticas. O que buscamos a partir de agora são as "as coisas mesmas" tal qual elas se apresentam à nossa consciência. Para Husserl a consciência é intencional, ou seja, é sempre consciência de alguma coisa. Essa alguma coisa é um "fenômeno", aquilo que se mostra à consciência intencional. Portanto, o fundamental para a fenomenologia é descrever o que se mostra à consciência. O método que garante essa experiência é a epoché ou a "redução fenomenológica". Por meio dela encontramo-nos em condição de suspender os juízos da chamada "atitude natural", ou seja, toda a gama de crenças que orientam o nosso estar no mundo.

Esse procedimento permite a compreensão das coisas mesmas ou das essências, tendo se mostrado um caminho fecundo em psicoterapia, na medida em que fornece um caminho diferente daquele das ciências naturais que influenciou o desenvolvimento da psicologia. Com a suspensão dos nossos juízos e a proposição de uma atitude descritivo-compreensiva, aproximamo-nos das essências dos fenômenos que integram a nossa existência como um todo e que escapam ao reducionismo cientifico tradicional. A partir de então pudemos, enfim, superar os limites da objetividade científica sem abrir mão do rigor do conhecimento. Devemos nos lembrar que Husserl mantinha a sua preocupação de garantir a objetividade desse conhecimento subjetivo, o que resolvia por meio da intersubjetividade (Husserl, 2001). Assim, ampliamos os limites da ciência por meio da subjetividade transcendental que realiza a redução fenomenológica, mas não abrimos mão de nos certificarmos que chegamos às coisas mesmas.

Todavia, uma suspeita permanece: a redução fenomenológica não perseguiria ainda o ideal da neutralidade científica característico das abordagens positivistas? De fato, Husserl mesmo afirmou ser a fenomenologia o verdadeiro conhecimento positivo (2006). Todavia, sabemos que, com a expressão "positivo", ele não se referia ao modelo naturalista das ciências empíricas, posto que re- mete a sua fenomenologia às essências eidéticas e ao ego transcendental. Ora, mesmo abrindo mão do modelo naturalista de experimentação científica e priorizando não o objeto positivo, tal qual a ciência empírica o entende, mas sim a intuição das essências eidéticas pelo sujeito transcendental, percebemos ainda, na fenomenologia, a busca por um rigor que garanta o conhecimento e possa afirmar a certeza apodídica. Como afirma Depraz,

A originalidade da fenomenologia husserliana se atém a seu caráter essencialmente descritivo. Em busca das invariáveis de nossa experiência, ela elabora um método eidético que livra a descrição de todo empirismo; em busca do sentido de ser da subjetividade, ela forja um método transcendental de constituição e exime o sujeito de todo o resíduo substancial, fazendo dele um eu operante. Esses dois passos metódicos remetem à execução de uma redução radical do factual e do substancial. O eidético serve de hermenêutica mínima, onde se explicita em categorias descritivas os sentidos da experiência. (2007, p. 89, grifos meus).

A fenomenologia seria, portanto, como propôs Husserl, uma ciência rigorosa, embora, obviamente, não no sentido naturalista criticado pelo filósofo.

O que suspeitamos é que temos na epoché um "eu asséptico", purificado das suas crenças que impediriam a intuição das "coisas mesmas". O ser do mundo, para Husserl, consiste em seu sentido que é "constituído" no ego transcendental e reflete uma preocupação eminentemente epistemológica. Parece-nos, portanto, que apesar da consciência intencional apontar para a superação da clássica cisão entre sujeito e objeto talvez, de fato, não realize essa superação. A cisão sujeito-objeto, tão cara ao modelo moderno, é o abismo que garantiria a objetividade do conhecimento de um objeto não contaminado pelos vícios subjetivos que turvam a visão de quem conhece. Suspeitamos que a fenomenologia, apesar da intenção de superação dessa cisão por meio da consciência intencional, enquanto aponta para a superação desse abismo trazendo o sujeito para o diálogo com o objeto a ser compreendido por meio da intencionalidade da consciência, não consegue, todavia, livrar-se do ranço cientificista do ideal asséptico. A pretensão de neutralidade ainda impera na fenomenologia e nos faz acreditar que possa haver "a coisa mesma" que se mostra a uma consciência, por sua vez, também capaz de suspender as suas crenças sobre o mundo.

A partir da consideração do que foi dito, pretendemos refletir sobre um caminho que aponte para a superação desse modelo de neutralidade ainda cientificista, um caminho que resgate não apenas o sujeito e a compreensão como forma de aproximação dos fenômenos, o que a fenomenologia de Husserl fez muito bem, mas que resgate também ou mesmo fundamentalmente a própria experiência prévia do mundo como um valor a ser agre- 
gado à compreensão do mundo e do outro. A nossa précompreensão do mundo não poderia significar uma condição afirmativa e, portanto não restritiva na nossa aproximação dos fenômenos? A nossa atitude natural diante do mundo, aquela que Husserl pretende suspender por meio da epoché fenomenológica, já anuncia em si mesma uma pré-compreensão dos fenômenos, que talvez deva ser considerada ao invés de suspensa. É o que nos sugere a hermenêutica de Heidegger, cuja conciliação com a fenomenologia não se faz sem transformações profundas no que diz respeito à superação do modelo sujeito-objeto e da própria fenomenologia de Husserl.

Reparem que falamos de "pré-compreensão" e não de "preconceito" como nos sugeriria a leitura de Gadamer da hermenêutica (Grondin, 1999), onde os preconceitos são confrontados com a coisa mesma para serem purificados. A "pré-compreensão" é um termo heideggeriano e remete a uma hermenêutica que não deixa de ser uma fenomenologia, mas que transforma essa fenomenologia acrescentando-lhe a interpretação prévia do mundo como uma condição positiva e constitutiva da compreensão. Essa interpretação nos conta que na lida com o mundo já estamos sempre em uma pré-compreensão daquilo que queremos conhecer. Não falamos, portanto, de um preconceito, mas falamos que a nossa própria lida com os fenômenos já nos coloca nesse âmbito de uma compreensão prévia. Essa compressão prévia não pode e nem deve ser eliminada da nossa lida com as coisas, posto que é ela que nos garante a compreensão do fenômeno que se nos apresenta sempre, estejamos nós nas nossas relações cotidianas ou em nosso consultório. Portanto, não há nada para ser colocado "entre parêntese", como sugeriria uma atitude fenomenológica tradicional, ou mesmo "purificado", como proporia, por exemplo, uma hermenêutica gadameriana. O fenômeno se mostra sempre a partir da nossa pré-compreensão que se instaura na nossa própria lida com o mundo e que é condição de possibilidade da compreensão do sentido.

E como é possível que se dê essa pré-compreensão? Para responder a essa questão precisamos considerar alguns dos elementos fundamentais da filosofia de Heidegger que ficam ainda mais claros se comparados com a filosofia de Husserl. Como afirma Depraz,

Husserl havia questionado a concepção clássica da consciência entendida como interioridade encerrada em si própria, opondo-lhe uma subjetividade intencional, quer dizer, originariamente aberta aos objetos percebidos; Heidegger radicaliza essa crítica do cartesianismo acentuando o movimento de abertura do mundo: a estrutura intencional da subjetividade lhe parece ainda demasiado marcada pela distinção remanescente do sujeito e do objeto herdada das filosofias da representação. Ele também propõe mudar o nome que se dá habitualmente à instância intersubjetiva: o ego husserliano se torna Dasein, um 'existente', literalmente, um 'ser-aí'. O encapsulamento que traz em si o termo ego, o resíduo de substancialidade que contém a palavra 'sujeito', se vêem novamente postas em causa pela noção de Dasein. Como o indica 'exsistente', a instância em questão é desdobrada, aberta, 'de fora' (ex-istens): não há mais nem mesmo dentro. (...) O Dasein está originariamente fora, tendo abandonado toda reserva, toda tela que desse a entender que há um 'dentro'. Ele é essa pura dinâmica de autotranscendência, e o mundo sua inscrição móvel originária, ao ponto de se 'compreenderem' um pelo outro. (2007, p. 89-90).

Para a ontologia fundamental, nós somos um ente que tem por modo de ser o que Heidegger chama de ser-aí. $\mathrm{O}$ ser-aí não é uma substância ou uma essência metafísica, nem tampouco uma determinação empírica, mas um existente. O ser-aí ek-siste, ou seja, pro-jeta-se. Somos o aberto de um pro-jeto lançado, uma seta que parte sem que sequer possa ser delimitado o ponto do qual partiu. Não há, portanto, o ponto de partida, mas o projetar, o lançamento não apreensível.

Assim, o ser-aí se dá como aquele que transcende. Transcendência significa "ultrapassagem", ou seja, falamos sobre um modo de ser que de modo algum pode permanecer, visto que é abertura, pro-jeto lançado, embora, de toda forma, também não possa abandonar o seu lugar, uma vez que não se resume a um nada no sentido de um niilismo puramente negativo.

O horizonte em direção ao qual se dá a ultrapassagem é o mundo. Na transcendência, portanto, o ser-aí desvelase como ser-no-mundo. Mas o que se entende por mundo? Certamente mundo não é uma determinação espacial, como também não é um somatório de entes. Mundo não é, ainda, um ente entre outros. Falamos daquilo que permite a abertura dos diversos contextos ontológicos dos entes, ou seja, dos diferentes modos de ser dos diferentes entes. Mundo é, assim, "a abertura do ente enquanto tal na totalidade" (Heidegger, 2003, p. 326), sendo que "na totalidade" diz "a forma do ente enquanto tal que se manifesta para nós" (Heidegger, 2003, p. 326). Mundo é o acontecimento das coisas e diz respeito a um modo de ser do ser-aí. Ser e mundo compõem uma unidade. O seraí é seu mundo.

Não temos, portanto, mundo de um lado e sujeito do outro, mas temos um modo de ser que já é, como acontecimento, algo que está lançado e em intima relação com os outros modos de ser. Assim, todo o problema do conhecimento que se funda na cisão sujeito-objeto perde o seu sentido. Ser-no-mundo é, ao mesmo tempo, compreender mundo. Como diz Heidegger,

ao dirigir-se para... e apreender, o ser-aí não sai de uma esfera interna em que antes estava encapsulado.

Em seu modo de ser originário, o ser-aí já está sempre 'fora', junto a um ente que lhe vem ao encontro 
no mundo já descoberto. E o deter-se determinante junto ao ente a ser conhecido não é uma espécie de abandono da esfera interna. De forma alguma. Neste 'estar fora', junto ao objeto, o ser-aí está ‘dentro' num sentido que deve ser entendido corretamente, ou seja, é ele mesmo que, como ser-no-mundo, conhece. E, mais uma vez, a percepção do que é conhecido não é um retorno para a ‘cápsula' da consciência com uma presa na mão, após ter saído em busca de apreender alguma coisa. De forma alguma. Quando em sua atividade de conhecer, o ser-aí percebe, conserva e mantém, ele, 'como ser-aí, permanece fora'. Tanto num mero saber acerca do contexto ontológico de um ente, num 'mero' representar a si mesmo, num 'puro' 'pensar' em alguma coisa, como numa apreensão originária, eu estou fora no mundo, junto ao ente. (2000, Parte I, p. 101).

São o estar fora do ser-aí e a sua intimidade com o mundo a condição de possibilidade da compreensão prévia, o que faz da fenomenologia também uma hermenêutica.

Ao transpor essa reflexão para a prática clínica damonos conta de uma atitude nova a ser assumida pelo psicoterapeuta. Ele descobre que não há a "coisa mesma” que precisa ser intuída pela consciência, mas que há algo que acontece no espaço terapêutico e que diz respeito ao encontro entre terapeuta e cliente. Quando se dá o encontro o terapeuta já se descobre em uma pré-compreensão da experiência existencial do outro e, partindo dessa mesma pré-compreensão, deixa emergir o que parecia oculto. Essa emergência é a própria compreensão que se instaura no diálogo com o cliente sempre a partir da consideração desse âmbito prévio que circunscreve o encontro. Portanto a pré-compreensão é um elemento fundamental da psicoterapia que não pode ser suspenso ou purificado.

O ideal da neutralidade científica, na verdade, só nos afasta da compreensão do fenômeno que queremos esclarecer. Ele pressupõe a cisão sujeito-objeto que, por sua vez, cria o problema do conhecimento. Mas, se pensarmos a partir de outro modelo onde a cisão não acontece, como o modelo heideggeriano, o problema do conhecimento perde o seu sentido, pois não precisamos mais nos reportar a algo que em si mesmo está separado do sujeito, posto que tudo o que há é constitutivo da nossa experiência de mundo. Essa é a grande contribuição de Heidegger para a compreensão do problema do conhecimento, pois o problema se deve justamente ao estabelecimento e, portanto, à necessidade de superar a cisão entre, de um lado, um sujeito que conhece e, de outro, um objeto que está aí para ser conhecido. E se não há algo que nos escapa, o objeto de conhecimento, tampouco pode haver crenças que precisam ser suspensas para não turvar a nossa intuição das essências. Tudo o que experimentamos já é uma experiência do ser das coisas. O terapeuta não é apenas uma consciência capaz de descrever os fe- nômenos, mas é aquele que na sua compreensão prévia da experiência existencial do cliente já está lá, com ele, mergulhado na riqueza dos seus significados que só se abrem no encontro.

Mas o que queremos dizer? Podemos nos transpor para a intimidade de outra pessoa? Podemos saber o que se passa ali? Como é possível compreender o outro no seu modo de ser? A essa indagação, Heidegger nos responde:

Se um homem existe, ele já está transposto enquanto um existente para o interior de um outro homem; mesmo que não haja faticamente nenhum outro homem por perto. Por isto, o ser-aí do homem significa - não exclusivamente, mas entre outras coisas - ser transposto para o interior de outros homens. O podertranspor-se para o interior de outros homens como um acompanhamento deles, do ser-aí neles, já sempre acontece em virtude do ser-aí do homem - enquanto ser-aí. Pois ser-aí significa: ser-com-os-outros; e, em verdade, sob o modo do ser-aí, isto é, co-existir. A pergunta sobre se nós, homens, podemos nos transpor para o interior de outros homens é indiscutível porque não é nenhuma pergunta possível. Ela é sem-sentido, mesmo absurda. (2003, p. 237).

Poderíamos indagar se essa atitude não anuncia a própria fenomenologia. A compreensão prévia não corresponderia à intuição das essências? Na verdade não, pois não há mais a "coisa mesma” para a consciência intencional. Não há mais nem mesmo a consciência intencional. Em Heidegger, o modelo sujeito-objeto, que ainda permanece em Husserl, foi completamente superado a ponto de não ser mais possível a pergunta pela "coisa mesma" ou pelo sujeito que a conhece. A compreensão prévia é a própria confirmação de que não há mais nenhum abismo a ser superado. Portanto, não há também a necessidade da compreensão de algo que "nos escapa" obscurecido pela nossa atitude natural. Nada nos escapa, mas tudo está simplesmente aí, aberto a nossa compreensão. Este é propriamente o âmbito prévio a que nos referimos.

Portanto, se esse modo de compreender os fenômenos é constitutivo do nosso ser, como nos sugere Heidegger, nada precisamos fazer - nem reduções fenomenológicas nem purificações hermenêuticas - para compreender o sentido. Na verdade, precisamos trilhar o caminho inverso: abdicar dos artifícios que nos fazem duvidar da nossa compreensão prévia.

A fenomenologia, porque é também hermenêutica, abandona a sua pretensão original de fundamento radical do conhecimento e se assume como uma atitude que diz respeito ao nosso próprio modo de ser. Como afirma Stein,

o ser-aí não é presença originária, como o eu transcendental de Husserl. Seu ser é temporalidade e não é seu próprio fundamento, porque acontece como his- 
toricidade indisponível. O aí do ser-aí, que é abertura sem a qual não se dá a relação do ente, surge de um âmbito a partir do qual o ser-aí se encontra consigo mesmo. Então, se impõe claramente que o ser-aí não pode exercer a função do fundamento, o que ainda era típico da subjetividade da filosofia moderna e da fenomenologia de Husserl. (1968, p. 39).

Portanto, não está mais em jogo a intencionalidade da consciência, mas a própria lida com o mundo por meio do que Heidegger chamou de "disposição afetiva" (2000, p. 188-194). Estamos aí, na abertura do mundo, dispostos a sermos afetados por ele e a dele cuidar.

A compreensão que se abre nesse processo também não é epistemológica, como em Husserl, mas existencial. Enquanto Husserl privilegia a redução fenomenológica que garante o distanciamento do sujeito de si mesmo, Heidegger insiste na angústia e no tédio como disposições afetivas fundamentais de um modo de ser que não pode mais ser reduzido à instância da subjetividade. Para Heidegger, não interessa a exatidão do conhecimento das essências, não interessa a certeza apodídica, mas a compreensão do sentido que, diferentemente de Husserl, é sempre existencial e aproximativo - e não epistemológico e apodídico - posto que a verdade não é mais algo dado que possa ser intuído como uma essência eidética, mas o jogo continuo de velamento e desvelamento dos modos de ser que se dão no encontro por meio das disposições afetivas e não da consciência. Se há a “coisa mesma”, ela é o que se manifesta no próprio encontro e que não exige do terapeuta nada além do que a sua disposição de ser afetado pelo que lhe vem ao encontro dentro do mundo e, por sua vez, abre o âmbito da compreensão prévia e da própria compreensão.

Poderíamos ainda indagar como se dá esse efetivamente esse processo. É o que agora tentaremos esclarecer. A fenomenologia hermenêutica de Heidegger se apóia no “circulo da compreensão" que pressupõe o fato de já estarmos desde sempre em uma compreensão prévia daquilo que desejamos compreender, como já sugerimos. Para entender que toda interpretação é fundada em uma précompreensão que, por sua vez, não deve ser lida em sentido epistemológico, precisamos entender que "compreender", para o filósofo, significa "poder lidar com algo". Portanto, a compreensão assume mais o sentido de um "situar-se no mundo" do que de um conhecimento e expressa a lida com o mundo e com os outros.

As pré-compreensões, abarcadas pelo círculo hermenêutico, são expressões das nossas relações com o mundo. Entretanto, para Heidegger, não somos envolvidos pelas nossas pré-compreensões como por "preconceitos" que precisam ser "purificados", como sugere a leitura hermenêutica de Gadamer, mas a hermenêutica de Heidegger visa ao "esclarecimento" daquilo mesmo que já é pré-compreendido, antes de tomar a pré-compreensão como algo já dado que deve ser confrontado com a coisa mesma. A pré-compreensão não é a expressão de uma subjetividade, mas remete à "coisa mesma" que apenas precisa ser esclarecida, lembrando sempre que a “coisa mesma” não é jamais um objeto de conhecimento dado a priori, mas algo que nasce do próprio encontro. Assim, a interpretação acontece a partir da pré-compreensão, que é uma primeira compreensão, com o fim de torná-la transparente e, então, alcançar a compreensão. Essa circularidade é ontológica e pertence ao modo de ser do ser-aí.

A hermenêutica é, portanto, uma oportunidade de esclarecimento do ser-aí na sua própria facticidade. Assim, o ser-aí tem a possibilidade de auto-esclarecimento e do esclarecimento do seu ser-no-mundo em meio às suas possibilidades e relações, podendo ir além da condição em que se encontra na maior parte das vezes e na qual o ser permanece esquecido. Porém, Heidegger (2003, p. 333-344) adverte que cabe a cada ser-aí abrir o "seu” caminho para a autotransparência e, com a finalidade de proteger a apropriação pessoal dessa possibilidade, introduz os seus conceitos como "indicadores formais" que, antes de indicar "algo presente", evocam uma experiência e possibilitam a compreensão. Portanto, os conceitos filosóficos, na ontologia fundamental, são indicadores que somente podem ser assumidos de modo particular, por empenho e responsabilidade pessoal (Grondin, 1999, p. 169). Eles dizem respeito apenas a uma compreensão possível que assume o caráter, nas palavras de Grondin, de indicação hermenêutica.

A circularidade da compreensão significa que não seguimos linearmente em um sentido progressivo, mas eksistimos e compreendemos em um vai-e-vem incessante imerso em um pensar circular. Todavia, ainda precisamos esclarecer: o pensar circular tampouco é um modo de nos movermos que nos lança de um lado a outro sem que cheguemos a algum lugar. Não se trata, portanto, de um círculo vicioso, em que sempre retornamos ao ponto de partida sem, no fundo, sairmos do nosso ponto inicial. Em verdade, o círculo hermenêutico permite, como defende Heidegger (2003, p. 217-218), o "olhar para o centro", o que somente se faz possível em um movimento circular.

A proposta fenomenológico-hermenêutica termina, então, por sugerir a compreensão como uma construção contínua, um processo incessante de esclarecimento de todo modo inconcluso, mas, nem por isso, impossível. A imagem que talvez possa ser adotada é a de uma espiral, na qual, movendo-nos em um contínuo vai-e-vem, voltamos ao ponto de partida e, ao mesmo tempo, não voltamos, pois algo novo aconteceu e não nos encontramos mais no início. Encontramo-nos lá e, ao mesmo tempo, não nos encontramos, porém, sem que esse movimento que reflete o nosso próprio modo de ser implique a esterilidade de um giro vazio que nada acrescenta. Contudo, ao adotarmos a imagem de uma espiral, também não pretendemos afirmar que nos encontramos à frente ou atrás. 
O círculo da compreensão não traz nenhuma noção "necessária” de progresso e evolução, tanto quanto não traz uma noção "necessária” de regressão. Estamos em uma "outra perspectiva" e isso é tudo.

O círculo hermenêutico é o nosso próprio modo de ser-no-mundo. Assim, em Heidegger, a compreensão abandona o seu posto epistemológico para traduzir o nosso próprio modo de ser. Somos compreensão em um movimento circular.

E quais são as implicações dessa interpretação para a prática clínica? Ora, o circulo hermenêutico, na medida em que pressupõe a compreensão a partir do esclarecimento da nossa pré-compreensão em um movimento circular, abre o entendimento da experiência existencial do cliente como um processo contínuo e inconcluso, portanto, aproximativo. Não há um ponto de chegada, mas um movimento circular que sempre novamente se propõe. Porém, ao mesmo tempo, não há a impossibilidade da compreensão visto que, pela compreensão prévia que nasce do fato de já sempre estarmos lançados no mundo sem qualquer separação daquele com o qual nos relacionamos, estamos sempre em algum nível de compreensão dos fenômenos. Essa compreensão, pelo próprio círculo hermenêutico, evolui incessantemente sem que dela possamos fazer algum juízo de valor. Não podemos afirmar uma evolução linear, mas apenas circular, ou seja, como dito, estamos em outro momento, apenas isso. Esse tipo de aproximação terapêutica oferece uma atitude acolhedora e não julgadora em relação às experiências do cliente, em que o sentido se desvela sem que seja possível a afirmação de uma resposta definitiva. E esse sentido, uma vez desvelado, assume a cada vez novos significados que vão sendo experimentados a cada encontro.

É como se o cliente tecesse uma rede em que os fios assumem incontáveis direções e, com a ajuda do psicoterapeuta, fosse esclarecendo os sentidos compreendidos nessa grande trama. $\mathrm{O}$ psicoterapeuta acompanha o cliente na pergunta pelo sentido das suas experiências e da sua existência. E o acompanha de tal forma que a circularidade da interpretação, enquanto não oferece uma resposta definitiva, mas apenas compreensões aproximativas, e nem por isso menos verdadeiras, liberta-o para a criação da sua existência que nada mais é do que uma abertura de possibilidades.

\section{Referências}

Depraz, N. (2007). Compreender Husserl. Petrópolis: Vozes.

Grondin, J. (1999). Introdução à Hermenêutica Filosófica. Rio Grande do Sul: Unisinos.

Heidegger, M. (2000). Ser e Tempo. Petrópolis: Vozes.

Heidegger, M. (2001). Seminários de Zollikon. Petrópolis: Vozes.
Heidegger, M. (2003). Conceitos Fundamentais da Metafísica. Rio de Janeiro: Forense Universitária.

Husserl, E. (1997). La Crisi delle Scienze Europee e La Fenomenologia Trascendentale. Milano: EST.

Husserl, E. (2001). Meditações cartesianas: introdução à fenomenologia. São Paulo: Madras.

Husserl, E. (2006). Idéias para uma fenomenologia pura e para uma filosofia fenomenológica. São Paulo: Idéias \& Letras.

Husserl, E. (2008). A crise da humanidade européia e a filosofia. Porto Alegre: EdiPUCRS.

Reale, G. (2003). História de Filosofia (Vol. 3). São Paulo: Paulus.

Stein, E. (1968). Possibilidades de uma nova ontologia. Revista Organon, 12, Porto Alegre.

Luciana da Silva Mendes Ferreira - Psicóloga clínica e professora de filosofia dos cursos de graduação e de pós-graduação em Filosofia da Universidade Católica de Brasília (UCB). Graduada em Psicologia (1993), possui o título de Especialista em Filosofia e Existência pela Universidade Católica de Brasília (UCB, 2005), de Especialista em Filosofia pela Universidade de Brasília (UnB, 2005), além do título de Mestre em Filosofia também pela Universidade de Brasília (UnB, 2008). Endereço Institucional: Universidade Católica de Brasília, Faculdade de Filosofia. QS 07, Lote 1 - Águas Claras - CEP: 70775-080. Email: lusmferreira@yahoo.com.br

Recebido em 10.06.09

Primeira Decisão Editorial em 22.09.09 Aceito em 15.10.09 